\title{
A novel insight into the mechanism of mammalian selenoprotein synthesis
}

\author{
OLGA KOSSINOVA, ${ }^{1,2}$ ALEXEY MALYGIN, ${ }^{1}$ ALAIN KROL, ${ }^{2,3}$ and GALINA KARPOVA ${ }^{1,3}$ \\ ${ }^{1}$ Institute of Chemical Biology and Fundamental Medicine, Siberian Branch of the Russian Academy of Sciences, Novosibirsk, 630090, Russia \\ ${ }^{2}$ Architecture et Réactivité de I'ARN, Université de Strasbourg, CNRS, IBMC, 67084 Strasbourg, France
}

\begin{abstract}
The amino acid selenocysteine is encoded by UGA, usually a stop codon, thus requiring a specialized machinery to enable its incorporation into selenoproteins. The machinery comprises the tRNA ${ }^{\text {Sec }}$, a $3^{\prime}$-UTR mRNA stem-loop termed SElenoCysteine Insertion Sequence (SECIS), which is mandatory for recoding UGA as a Sec codon, the SECIS Binding Protein 2 (SBP2), and other proteins. Little is known about the molecular mechanism and, in particular, when, where, and how the SECIS and SBP2 contact the ribosome. Previous work by others used the isolated SECIS RNA to address this question. Here, we developed a novel approach using instead engineered minimal selenoprotein mRNAs containing SECIS elements derivatized with photoreactive groups. By cross-linking experiments in rabbit reticulocyte lysate, new information could be gained about the SBP2 and SECIS contacts with components of the translation machinery at various translation steps. In particular, we found that SBP2 was bound only to the SECIS in $48 \mathrm{~S}$ pre-initiation and $80 \mathrm{~S}$ pretranslocation complexes. In the complex where the Sec-tRNA ${ }^{\text {Sec }}$ was accommodated to the A site but transpeptidation was blocked, SBP2 bound the ribosome and possibly the SECIS element as well, and the SECIS had flexible contacts with the $60 \mathrm{~S}$ ribosomal subunit involving several ribosomal proteins. Altogether, our findings led to broadening our understanding about the unique mechanism of selenocysteine incorporation in mammals.
\end{abstract}

Keywords: mammalian ribosome; cross-linking approach; selenocysteine incorporation; selenocysteine insertion sequence; SECIS-binding protein 2

\section{INTRODUCTION}

Selenium is an essential micronutrient that exerts significant health benefits. Implicated in the prevention of cancer and male infertility, it has also been shown as an important factor for thyroid hormone maturation, the immune system, and muscle development and function (Papp et al. 2007; Lescure et al. 2009). The main biological form of selenium is the amino acid selenocysteine (Sec) (Zhang and Gladyshev 2011). Selenocysteine-containing proteins are found in the three domains of life, albeit not in all species. Selenocysteine is encoded by a UGA triplet that is generally recognized as a stop codon (Chambers et al. 1986). A specialized mechanism is, therefore, required to cotranslationally incorporate this amino acid into the nascent polypeptide chain. The mechanism has been decrypted in detail in bacteria (Böck et al. 2006). However, only the key players and not the mechanism have been identified so far in eukaryotes (Allmang et al. 2009). First, a 3'-UTR-located mRNA stem-loop called

${ }^{3}$ Corresponding authors

E-mail karpova@niboch.nsc.ru

E-mail a.krol@ibmc-cnrs.unistra.fr

Article published online ahead of print. Article and publication date are at http://www.rnajournal.org/cgi/doi/10.1261/rna.036871.112.
SECIS (SElenoCysteine Insertion Sequence) is mandatory for selenoprotein synthesis. Second, decoding of UGA Sec requires the specialized elongation factor eEFSec that delivers the Sec-tRNA ${ }^{\mathrm{Sec}}$ to the ribosomal A site (Fagegaltier et al. 2000a; Tujebajeva et al. 2000; Gonzalez-Flores et al. 2012) and the SECIS binding protein 2 (SBP2) that interacts with eEFSec, the SECIS, and the ribosome (Copeland et al. 2000, 2001; Caban et al. 2007; Takeuchi et al. 2009; Gonzalez-Flores et al. 2012). SBP2 was characterized in rat, humans, and Drosophila (Copeland et al. 2000; Lescure et al. 2002; Takeuchi et al. 2009). The mammalian SBP2 is $\sim 850$ aa long and contains two domains. The C-terminal domain is necessary for interaction with the ribosome (Copeland et al. 2001; Caban et al. 2007; Takeuchi et al. 2009) and also contains two modules important for SECIS binding. The first module, called L7Ae, is shared by ribosomal proteins L7Ae and L30 and several core proteins of sn- and snoRNPs (Allmang et al. 2002). The second module, called either the bipartite RNA binding domain (Bubenik and Driscoll 2007) or selenocysteine insertion domain (SID) (Donovan et al. 2008) or K-rich domain (Takeuchi et al. 2009), contains a conserved lysine-rich motif. The L7Ae module and an adjacent region were also predicted to contribute to the SBP2-ribosome interaction (Copeland et al. 
2001; Caban et al. 2007). The SBP2 N-terminal domain is dispensable for selenoprotein synthesis in reticulocyte lysate (Copeland et al. 2000) and its function is still unknown. Regarding binding of SBP2 to the ribosome, we showed it to bind exclusively the human $60 \mathrm{~S}$ but not the $40 \mathrm{~S}$ ribosomal subunit in vitro (Takeuchi et al. 2009). Recently, ribosomebound SBP2 was shown to increase the reactivity to acylation of the ribose $2^{\prime} \mathrm{OH}$ at specific residues of the $28 \mathrm{~S}$ rRNA located near the peptidyl-transferase center and $\mathrm{E}$ site, respectively (Caban and Copeland 2012).

Two different models for selenoprotein synthesis in eukaryotes have been proposed so far (Chavatte et al. 2005; Donovan et al. 2008). They converge on one aspect concerning delivery of the eEFSec $\cdot S e c-t R N A{ }^{\mathrm{Sec}} \cdot$ GTP complex to the ribosome in the course of selenoprotein mRNA translation. According to these models, when the ribosome pauses at the UGA Sec codon, the SECIS-bound SBP2 serves as a platform to recruit the eEFSec $\cdot S e c-t R N A{ }^{\mathrm{Sec}} \cdot \mathrm{GTP}$ complex to the ribosome.

However, the detailed mechanism of selenoprotein synthesis is still missing. In an attempt to bring some mechanistic

A

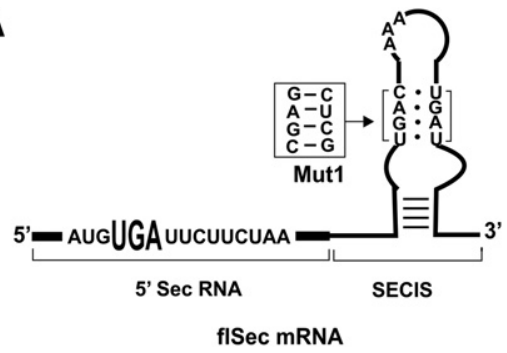

B
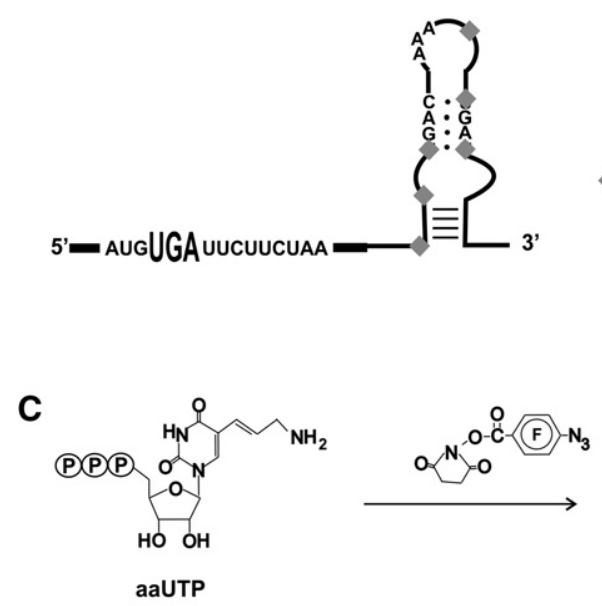

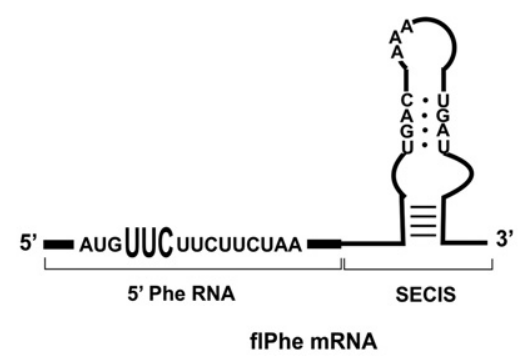

flPhe mRNA
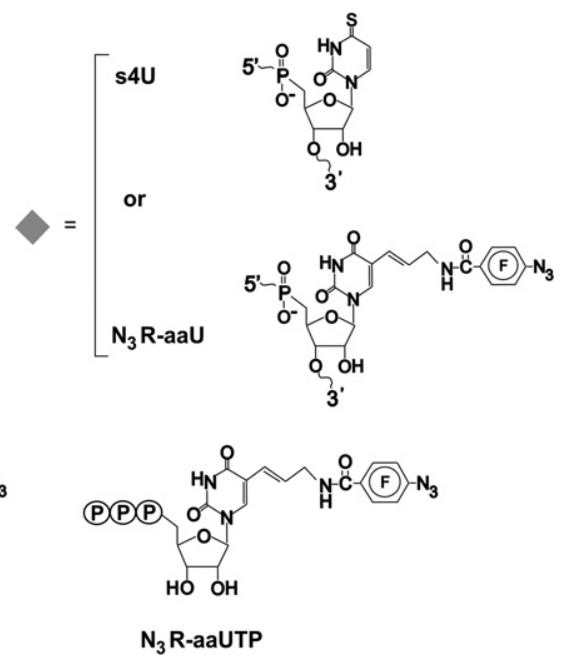

FIGURE 1. Schematic representation of the minimal mRNAs and their photoreactive derivatives used in this work. (A) Minimal mRNAs with WT GPx1 SECIS: flSec mRNA, mRNA carrying UGA Sec codon, and flPhe mRNA, mRNA carrying a Phe codon instead of UGA. SECIS-element of Mut l mRNA contains nucleotide residues shown in the box instead of residues shown in brackets. (B) Minimal selenoprotein mRNA containing photoreactive groups: 4-thiouridine residues $(\mathrm{s} 4 \mathrm{U})$ or aminoallyl-containing uridine residues bearing perfluorophenylazido group $\left(\mathrm{N}_{3} \mathrm{R}\right.$ aaU, where $\mathrm{R}$ is perfluorophenyl residue). (C) Schematic description of the synthesis of $\mathrm{N}_{3} \mathrm{R}$ aaUTP used as a substrate to obtain $\mathrm{N}_{3} \mathrm{R}$-aaU-containing SECIS. insight, the work described here focuses on different translational steps. To this end, we developed a new approach using selenoprotein mRNAs instead of the isolated SECIS as in previous studies by others. Minimal selenoprotein mRNAs bearing a SECIS element with photoreactive groups were engineered and used for cross-linking to ribosomes in rabbit reWecyte lysate. Cross-linking experiments combined with translation. The data allowed us to propose new insights

\section{RESULTS}

\section{Design and synthesis of minimal selenoprotein mRNAs}

For studying the mechanism of selenoprotein synthesis in mammals, we decided to use minimal selenoprotein mRNA containing an $\mathrm{m} 7 \mathrm{G}$ cap, a $5^{\prime}$ UTR, a short open readng frame, and a $3^{\prime}$ UTR with the SECIS element (Fig. 1A). Full-length minimal mRNA was assembled by splint-aided T4 DNA ligation of two RNA segments ( $5^{\prime}$ Sec RNA or $5^{\prime}$ Phe RNA, and SECIS in Fig. 1A). The minimal mRNA contained a short $5^{\prime}$ UTR, which is A-rich to minimize secondary structure formation and selfassociation of mRNA (Bulygin et al. 2005), followed by (1) the AUGUGA UUCUUC sequence encoding the tetrapeptide Met-Sec-Phe-Phe, (2) a UAA termination codon, and (3) the SECIS element of the rat glutathione peroxidase 1 (GPx1) selenoprotein mRNA in the $3^{\prime}$ UTR (Walczak et al. 1998). The crucial parameters considered for the design of the minimal mRNA were the distances between the Sec codon and the SECIS element and between the Sec and the stop codons. In order to mimic as much as possible a genuine selenoprotein mRNA, the distances were chosen to most resemble those existing in the selenoprotein O mRNA (Castellano et al. 2008). In addition, as they are rather short, they facilitate DNA template synthesis. Sec was substituted for Phe in the control mRNA. The final mRNAs obtained were designated as flSec mRNA (full-length mRNA, containing the Sec codon) and flPhe mRNA (full-length mRNA, where Sec was replaced by a Phe codon), respectively (Fig. 1A). A mutant flSec mRNA (Mut1 mRNA), which contained four Watson-Crick base pairs in the central core of the SECIS instead of the four non-Watson-Crick base pairs (Walczak 
et al. 1996), was also constructed (Fig. 1A). The core represents the main binding site for SBP2, and mutations therein lead to impairment of SBP2 binding in vitro and selenoprotein synthesis in vivo (Walczak et al. 1998; Copeland et al. 2000; Fletcher et al. 2001; Allmang et al. 2002; Cléry et al. 2007).

\section{Ribosome binding activity of the minimal mRNAs in rabbit reticulocyte lysate}

The functional activity of the minimal mRNAs was assessed in micrococcal nuclease-treated rabbit reticulocyte lysate (RRL). RRL is amenable to studying selenoprotein synthesis because it contains all the necessary components except SBP2, which can be added as the recombinant protein (Copeland and Driscoll 2002). To freeze the ribosomes at various steps of translation, we used the following translation inhibitors: (1) the nonhydrolyzable GTP analog, GMPPNP, which inhibits translation at the stage of $48 \mathrm{~S}$ preinitiation complex formation (Anthony and Merrick 1992); (2) anisomycin, which blocks transpeptidation in the $80 \mathrm{~S}$ elongation complex (Anthony and Merrick 1992); and (3) emetine, which blocks translocation (Jimenez et al. 1977). Complexes obtained with the translational inhibitors were designated as $48 \mathrm{~S}$, 80S-I, and $80 \mathrm{~S}-\mathrm{II}$, respectively (Fig. 2A). First, we examined whether the minimal mRNAs can bind to ribosomes. To this end, RRL containing the added SBP2 and $5 \mathrm{mM}$ anisomycin was incubated with the uniformly ${ }^{32} \mathrm{P}$-labeled flSec and flPhe mRNAs. Subsequently, the ribosomal 80S-I complex was isolated by sucrose gradient centrifugation under conditions of complex stability. Analysis of the radioactivity in ribosome fractions showed that the extent of mRNA binding to the ribosomes was $\sim 0.35 \mathrm{~mol}$ mRNA per mol of ribosomes for both types of mRNAs (Fig. 2B).

Second, we asked whether the minimal mRNAs were phased correctly on the ribosome-in other words whether the AUG codon was positioned in the $\mathrm{P}$ site. Phasing was analyzed with the primer extension inhibition method (toe-printing). In this assay, $\mathrm{a}^{32} \mathrm{P}$-labeled primer is annealed to the mRNA down- stream from the assumed initiation site, and reverse transcriptase is used to extend the radioactive primer up to the mRNA position bound to the ribosome (Fig. 2C). In the presence of GMPPNP, a toe-print was detected mostly at positions $+16 /+17$ (Fig. 2C, lanes 1 and 5) with respect to the first nucleotide of the triplet positioned in the $\mathrm{P}$ site (the adenosine of AUG in this particular case), suggesting translation stopped at the stage of $48 \mathrm{~S}$ preinitiation complex
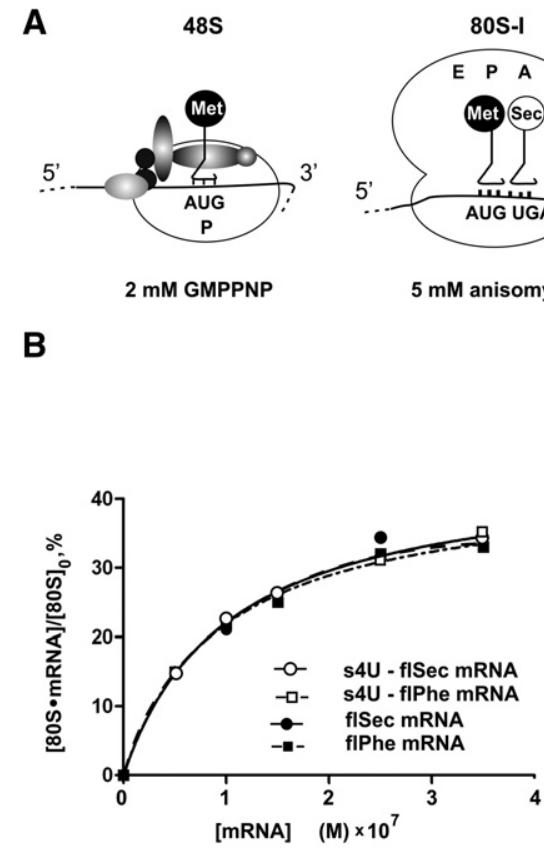

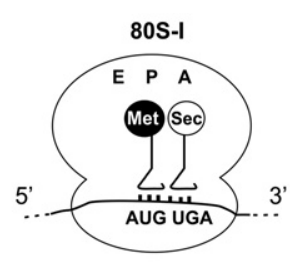

$5 \mathrm{mM}$ anisomycin

\section{C}

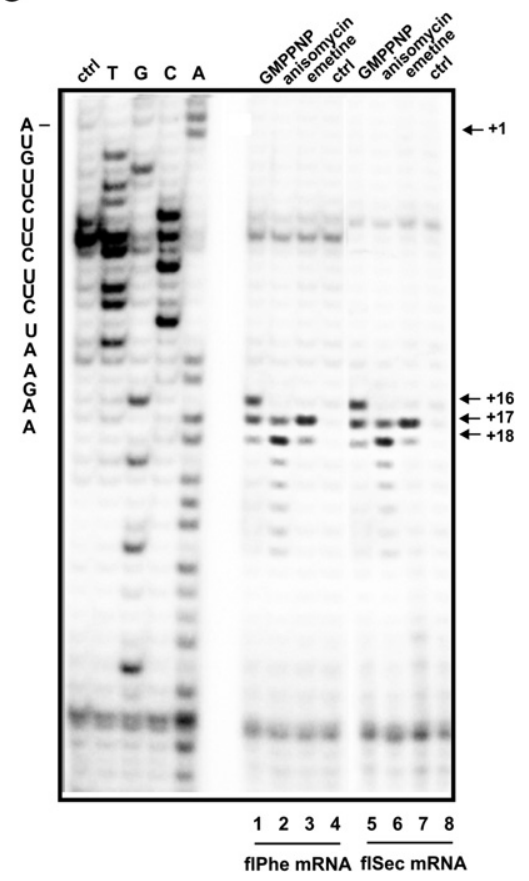

FIGURE 2. Ribosome binding abilities of the minimal selenoprotein mRNA. (A) Schematic representation of the complexes obtained from RRL with various translation inhibitors (concentration used is indicated). E, P, and A, tRNA binding sites. Initiation factors are displayed on the $48 \mathrm{~S}$ initiation complex. Charged tRNAs in $48 \mathrm{~S}$ and $80 \mathrm{~S}$-I complexes as well as deacylated tRNA and dipeptidyl tRNA in 80S-II complex are shown. (B) flSec mRNA (closed circles), flPhe mRNA (closed squares), s4U-containing flSec mRNA (s4U-flSec mRNA, open circles), and s4U-containing flPhe mRNA (s4U-flPhe mRNA, open squares) binding to ribosomes in RRL. Note that the concentration of the ribosomes in the RRL-based mixtures ( $50 \%$ of RRL v/v) was $\sim 0.05 \mu \mathrm{M}$. The data are the average of at least three independent experiments. The relative error was $\sim 10 \%$. $(C)$ Toe-printing assay of $48 \mathrm{~S}$ and $80 \mathrm{~S}$ complexes formed in RRL with flPhe mRNA (lanes 1-4) and flSec mRNA (lanes 5-8) in the presence of SBP2. Lanes 1 and 5: $48 \mathrm{~S}$ complex; lanes 2 and 6: 80S-I complex; lanes 3 and 7: 80S-II complex; translation inhibitors were omitted in lanes 4 and 8. (A,C, G,T) Sequencing lanes, (ctrl) primer extension with no ddNTP added. Arrows indicate the bands corresponding to toe-print signals. The two weak bands below the toe-prints in lanes 2 and 6 are assigned to signals corresponding to the post-translocational complexes that could be formed in insignificant amounts because of incomplete immobilization of ribosomes by anisomycin (by analogy with Kozak [1998] where lower concentrations of anisomycin were used). The strong signal in the upper part of the gel in the flPhe RNA toe-printing lanes may reflect partial degradation of the flPhe mRNA since it is present in all lanes with flPhe mRNA. 
formation (Dmitriev et al. 2003). The toe-print occurred mostly at positions +17 and +18 in the case of emetine or anisomycin, respectively, with respect to the adenosine of the AUG in the P site (Fig. 2C, lanes 2, 3, 6, 7), implying formation of the $80 \mathrm{~S}$ initiation complex (Dmitriev et al. 2003). It is unclear why the signal is stronger at +17 with emetine and at +18 with anisomycin; possibly, the difference in the intensities of the $80 \mathrm{~S}$ toe-print signals observed for the 80S-I and 80S-II complexes relate to different mechanisms of antibiotic action. These results indicate that in RRL, the AUG start codon of the minimal flSec mRNA was correctly positioned in the ribosomal $\mathrm{P}$ site, implying that the $3^{\prime}$ adjacent UGA Sec codon was in the A site. To check whether the A and P sites were indeed occupied by tRNAs, $\left[5^{\prime}-{ }^{32} \mathrm{P}\right] \mathrm{pCp}$ post-labeling was carried out on the $3^{\prime}$ end of total RNA isolated from 48S, 80S-I, and 80S-II complexes assembled in RRL with the flSec mRNA, in the presence of SBP2 (Fig. 3). The 80SI complex was also assembled on Mut1 mRNA (Fig. 1A) in

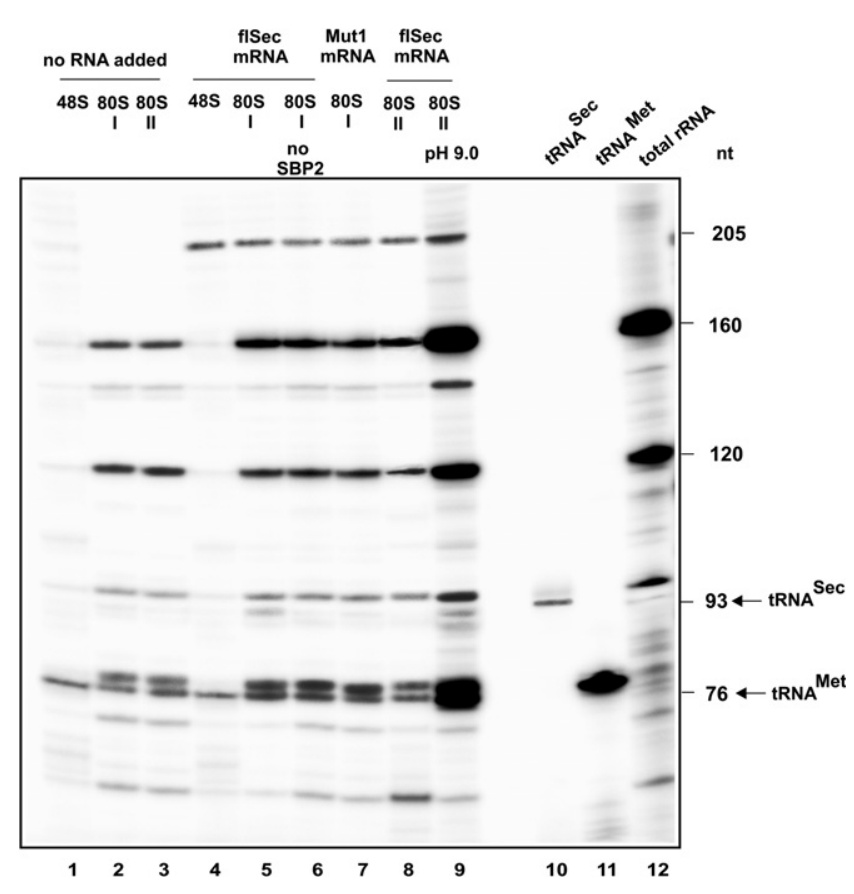

FIGURE 3. A-site occupancy by the tRNA ${ }^{\text {Sec }}$. Analysis was carried out on $\mathrm{Cu}^{2+}$-treated and $3^{\prime}$ end $\left[{ }^{32} \mathrm{P}\right]$-labeled RNAs isolated from $48 \mathrm{~S}$ and $80 \mathrm{~S}$ complexes assembled in RRL on the endogenous (lanes 1-3) or flSec mRNAs in the presence (lanes $4,5,8,9$ ) or absence (lane 6) of SBP2, or from the 80S-I complex formed on the Mut1 mRNA (lane 7). Lanes 1 and 4: 48S complex; lanes 2, 5-7: 80S-I complex; lanes 3, 8,9 (the sample was preliminarily treated at $\mathrm{pH} 9.0$ ): $80 \mathrm{~S}$-II complex (the weak bands observed in lane 9 but not in the other lanes could result from slight RNA hydrolysis at $\mathrm{pH}$ 9.0); lane 10: T7 tRNA ${ }^{\mathrm{Sec}}$ transcript ( $93 \mathrm{nt}$; it contains three additional Gs at the $5^{\prime}$ end compared to the authentic tRNA $\left.{ }^{\mathrm{Sec}}\right)$; lane 11: RNA $^{\mathrm{Met}}$ (76 nt); lane 12: total RNA isolated from $60 \mathrm{~S}$ subunits (5.8S rRNA, $160 \mathrm{nt}$; $5 \mathrm{~S}$ rRNA, $120 \mathrm{nt}$ ). Arrows indicate positions of the tRNA ${ }^{\mathrm{Met}}$ and $\mathrm{tRNA}^{\mathrm{Sec}}$. The band just above the tRNA ${ }^{\text {Sec }}$ observed in lanes 2, 3 and 5-9 might correspond to partial hydrolysis of the $28 \mathrm{~S}$ rRNA. The figure displays the autoradiogram corresponding to the part of the gel where RNA fragments with a length lower than $250 \mathrm{nt}$ were resolved. the presence of SBP2. Prior to labeling, total RNA was treated with $\mathrm{Cu}^{2+}$ to catalyze alkaline hydrolysis of the aminoacyltRNA ester bond. This cation was shown to catalyze hydrolysis of the aminoacyl moiety in aminoacyl-tRNAs (Schofield and Zamecnik 1968) but is unable to do so for the ester bond between a dipeptide and a tRNA because of the large distance between the free amino group and the ester bond (see Lapidot and de Groot 1972 and references therein). In control experiments, post-labeling was performed with total RNA isolated from the endogenous complexes obtained in micrococcal nuclease-treated RRL in the presence of GMPPNP or antibiotic. Despite the high level of labeling of the endogenous tRNAs isolated from control complexes (Fig. 3, cf. lanes 1-3 and lanes 4-9), one can clearly distinguish the presence of a band migrating at the level of the T7 tRNA $^{\text {Sec }}$ transcript, which shows up with the 80S-I complex assembled on flSec mRNA in the presence of SBP2 only (Fig. 3, cf. lane 5 with lane 10 and lane 5 with lanes 6 and 7). Note that the appearance of this band is SBP2-dependent since Mut1 mRNA, which contains substitutions in the SECIS inhibiting SBP2 binding, obliterated it. Absence of this band in lane 8 (80S-II complex) and its reappearance in lane 9 (after alkaline hydrolysis of the ester bond in the dipeptidyl-tRNA isolated from 80S-II complex) strongly argues in favor of the A site occupation by a dipeptidyltRNA $^{\mathrm{Sec}}$ whose ester bond could not be hydrolyzed by the action of $\mathrm{Cu}^{2+}$. It is worth mentioning here that the $\mathrm{RNA}^{\mathrm{Sec}}$ transcript migrated slightly slower than the endogenous tRNA $^{\text {Sec }}$ because the transcript contains three additional Gs at the very $5^{\prime}$ end in order to stimulate T7 transcription. All this allowed us to conclude that the flSec mRNA was able to form functional ribosomal complexes, where the $\mathrm{P}$ or $\mathrm{P}$ and A sites were occupied by the cognate tRNAs.

Lastly, we verified whether the complexes formed in the course of flSec mRNA translation contain SBP2. To this end, we sought to detect the presence of SBP2 in the 48S, 80S-I, and 80S-II complexes described above. In control experiments, we used ribosomes isolated from emetine- and SBP2-containing RRL (with no minimal mRNA added) and from a pretranslocation 80S-II complex formed with the $5^{\prime}$ Phe mRNA, a construct containing the UUC codon instead of UGA, and lacking the SECIS sequence (Fig. 4A). mRNA ribosome complexes were isolated from RRL by sucrose gradient centrifugation, and the presence of SBP2 in ribosome fractions was verified by Western blotting. Figure 4B (lanes 2-4 and 6) shows that SBP2 was present only in the complexes formed in the presence of the flSec mRNA but neither in the presence of the $5^{\prime}$ Phe mRNA (Fig. 4B, lane 7) nor in the absence of mRNA (Fig. 4B, lane 8 ), indicating that insertion of SBP2 in the complex was SECIS-mediated. It can be seen that the 48S, 80S-I, and 80S-II complexes (Fig. 4B, lanes 2-4) differed in the intensities of SBP2 signal, suggesting the different amounts of SBP2 in these complexes. To check whether emetine could block the ribosomal binding site of SBP2 in control complexes, 
we examined the binding of SBP2 with salt-washed ribosomes preincubated with emetine. It occurred that the presence of emetine did not change the ability of SBP2 to bind the ribosome (Fig. 4B, lanes 10 and 11). Confirmation of the SECIS-mediated SBP2 insertion in the ribosomal complex was also obtained by using the Mut1 flSec mRNA mutant (Fig. 1A). Figure 4C shows that, compared to the wild type (WT), the mutation did not impede much the binding of the mRNA to the ribosome in the presence of anisomycin (binding extent of $\sim 30 \%$ for the WT and Mut1). SBP2 was not detected in the ribosomal complex with Mut1 (Fig. 4C, lower panel), a finding that was expected since the mutation dramatically alters the SBP2 binding site (Allmang et al. 2002). Therefore, the flSec mRNA carrying the wild-type GPx1 SECIS element supports formation of ribosomal complexes in RRL with SBP2 binding in a SECIS-dependent manner. This mRNA can thus be used for investigating the SECIS and SBP2 contacts in the course of translation.

\section{SECIS-ribosome interactions during selenoprotein mRNA translation}

The 48S, 80S-I, and 80S-II complexes obtained with the flSec and flPhe mRNAs are depicted in Figure 2A. For the investigations described in this paragraph, the flSec mRNA harbored a uniformly ${ }^{32} \mathrm{P}$-labeled SECIS element that contained randomly inserted photoreactive $s 4 \mathrm{U}$ residues, enabling zerolength cross-links upon UV irradiation (Fig. 1B). The control flPhe mRNA was similarly prepared. The s4U-containing mRNAs displayed the same ribosome binding efficiency as the unmodified counterparts (Fig. 2B), meaning that introduction of s4U did not interfere with the mRNA-ribosome interaction. Both the flSec and flPhe mRNAs photoreactive derivatives, as well as the same derivatives of the isolated SECIS RNA, were able to cross-link to SBP2 in binary complexes upon irradiation with mild UV light (data not shown). To generate cross-links between the SECIS of the flSec mRNA and the other components of the complexes mentioned above, the reaction mixtures were irradiated under the same conditions.

After irradiation, complexes were separated from unbound components, and the presence of SBP2 in the complexes was confirmed by Western blotting (Fig. 5A). Proteins crosslinked to the SECIS element were analyzed by SDS-PAGE after RNase A hydrolysis of the RNA segments unprotected by the covalently linked proteins. With the $48 \mathrm{~S}$ (Fig. 5B, lane 2) and $80 \mathrm{~S}-\mathrm{II}$ (Fig. 5B, lane 6) complexes, the radioactive bands migrated at the level of the SBP2 marker (Fig. 5B, lane 9). For the $80 \mathrm{~S}$-I complex (Fig. 5B, lane 15), one can see two groups of radioactive bands migrating at the level of ribosomal proteins in the $10-20 \mathrm{kDa}$ range (Fig. 5B, lanes 24, 25). The bands, indeed, contained a protein moiety since proteinase $\mathrm{K}$ treatment prior to SDS-PAGE loading led to their disappearance (Fig. 5B, lanes 3, 4, 7, 8, 17, 18). Confirmation of the identity of the bands displayed in lanes 2 and 6 (Fig.

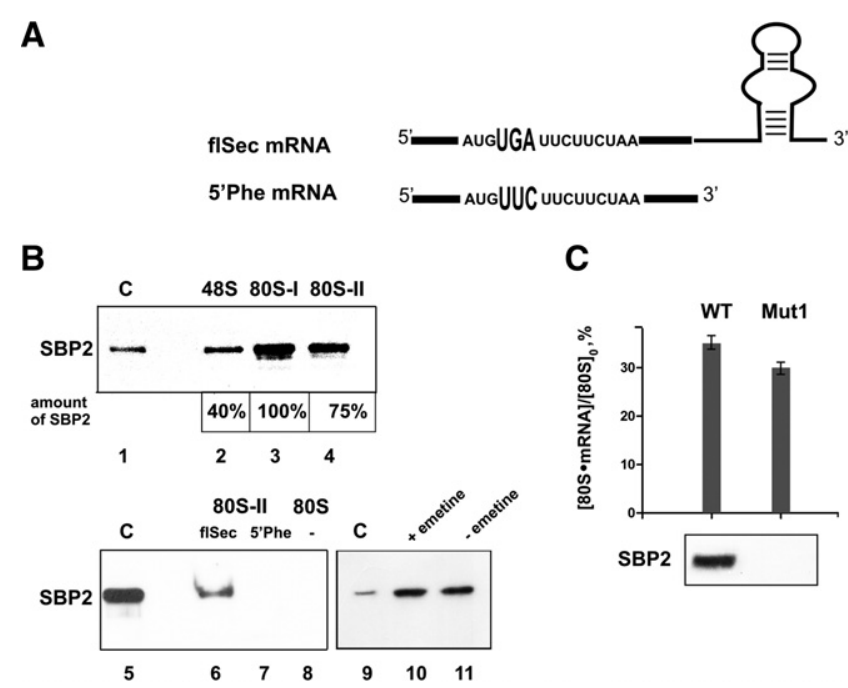

FIGURE 4. SBP2 content in ribosomal complexes formed in RRL. $(A)$ Minimal mRNAs used in the experiments. (B) The presence of SBP2 in complexes was shown by Western blotting with anti-SBP2 antibodies. Lanes 2, 3, 4, and 6, complexes with flSec mRNA: lane 2, $48 \mathrm{~S}$ preinitiation complex; lane 3, pretranspeptidation complex 80S-I; lanes 4 and 6, pretranslocation complex $80 \mathrm{~S}$-II; lane 7, 80S-II complex formed with the $5^{\prime}$ Phe mRNA; lane 8,80 S ribosomes isolated from RRL in the presence of emetine; lane $10,80 \mathrm{~S} \cdot \mathrm{SBP} 2 \cdot$ complex formed in the presence of $1 \mathrm{mM}$ emetine; lane $11,80 \mathrm{~S} \cdot \mathrm{SBP} 2 \cdot$ complex formed without emetine; lanes 1, 5, and 9, controls containing purified recombinant SBP2. The amount of SBP2 detected in the complexes is indicated below the panel; the amount of SBP2 detected in the 80S-I complex was taken as $100 \%$. (C) flSec mRNA WT and Mut1 mRNA binding to ribosomes in the presence of $5 \mathrm{mM}$ anisomycin (80S-I complex). The relative error in determining the binding extent of these mRNAs with ribosomes was $\sim 10 \%$. The data are the average of at least three independent experiments. The presence of SBP2 in 80S-I complexes was assayed by Western blotting with anti-SBP2 antibodies (shown in the lower panel).

5B) to SBP2 was brought by immunoprecipitation with anti-SBP2 antibodies of the total proteins from the irradiated $48 \mathrm{~S}$ and $80 \mathrm{~S}-\mathrm{II}$ complexes (Fig. 5C). The yield of SBP2 crosslinks with the SECIS in the $48 \mathrm{~S}$ and 80 S-II complexes was 2.3 \pm 0.3 times higher than the total yield of ribosomal protein cross-links with the SECIS in 80S-I complex; this was evaluated by densitometry of the gels shown in Figure 5B, taking into account the longer exposure time to detect cross-links with ribosomal proteins. Finally, the cross-links were specific because the bands were lacking in control lanes with the 80S-I complex formed with the s4U-containing flPhe mRNA (when the A site was occupied by the Phe-tRNA ${ }^{\mathrm{Phe}}$ ) in the absence (Fig. 5B, lanes 11-14) or presence (Fig. 5B, lanes 1922) of SBP2. In the latter case, a radioactive band migrating at the level of SBP2 was observed (Fig. 5B, lane 19) as in $48 \mathrm{~S}$ and $80 \mathrm{~S}-\mathrm{II}$ complexes with the flSec mRNA (Fig. 5B, lanes 2 and 6); confirmation that it corresponded to the cross-link of SBP2 with the s4U-containing SECIS element of flPhe mRNA was obtained by immunoprecipitation, as for complexes mentioned above (data not shown). This band appeared because SBP2 bound to the SECIS of this 
A

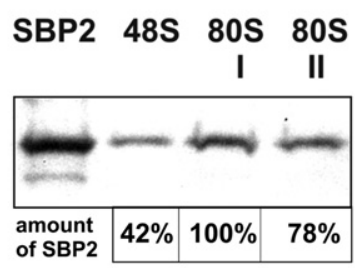

B

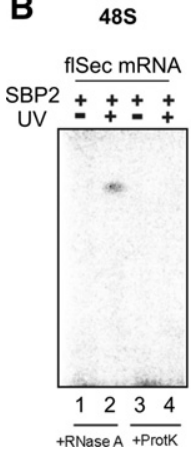

80S-II

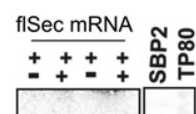

C cpm

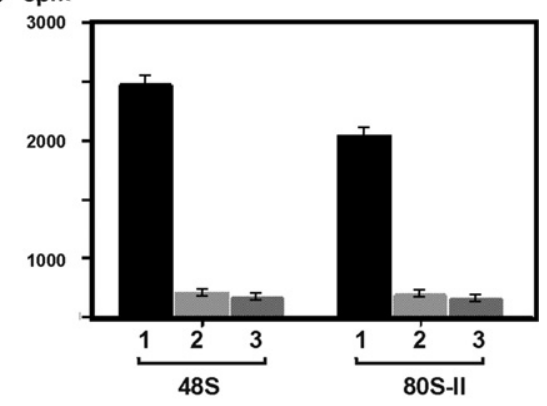

80S-I

flPhe mRNA flSec mRNA flPhe mRNA SBP2 $+: \pm+ \pm+ \pm+ \pm+ \pm$ कू UV

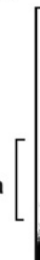

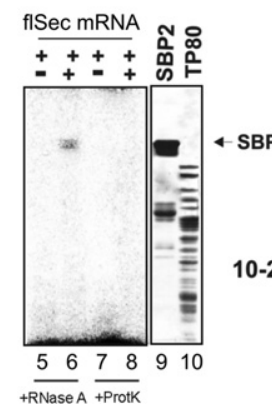
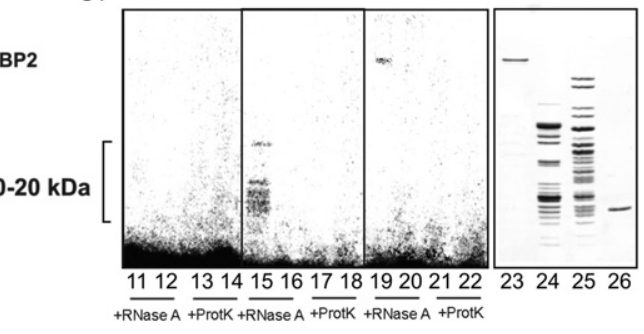

FIGURE 5. Cross-linking of minimal s4U-containing mRNAs in RRL. (A) The presence of SBP2 in complexes formed with the flSec mRNA shown by Western blotting. Lane 1: purified recombinant SBP2 as the control; lane 2: 48S complex; lane 3: 80S-I complex; lane 4: 80S-II complex. (B) Autoradiograms of the SDS-PAGE of the proteins cross-linked with the uniformly ${ }^{32} \mathrm{P}$-labeled s4U-containing SECIS of flSec mRNA (lanes 1-8 and 15-18) or flPhe mRNA (lanes 11-14 and 19-22), in the presence (+) or absence (-) of SBP2 and UV light. Exposure time: $12 \mathrm{~h}$ for the $48 \mathrm{~S}$ and $80 \mathrm{~S}$-II complexes, $48 \mathrm{~h}$ for the $80 \mathrm{~S}-\mathrm{I}$ complex. (+ RNase A or + Prot K) Complexes treated with RNase A or proteinase K, respectively. Lanes SBP2, L30 (ribosomal protein L30), TP80, TP60, and TP40 (total proteins from 80 S ribosomes, 60S, and 40S subunits, respectively) were Coomassie-stained. $(C)$ Validation of SBP2 cross-links obtained in 48S and 80S-II complexes by immunoprecipitation using anti-SBP2 antibodies. Bars 1: immunoprecipitation of the total proteins from the irradiated ribosomal complexes separated from unbound components; bars 2: same as in bars 1 but with beads lacking antibodies; bars 3: immunoprecipitation of the total proteins from the irradiated ribosome complexes obtained with flPhe mRNA but without SBP2. The data represent the mean and standard deviation of three independent experiments.

on denaturing 5\% PAGE. No SECISrRNA cross-link could be observed under such conditions (data not shown).

To determine which ribosomal subunit contacts the SECIS element, the 80S-I complex was formed using the flSec mRNA harboring a uniformly ${ }^{32} \mathrm{P}-$ labeled SECIS element with randomly inserted s4Us. After UV irradiation, the complex was isolated by sucrose gradient centrifugation and further run on a second sucrose gradient under conditions allowing ribosome subunit dissociation. Analysis of the gradient fractions revealed the presence of radioactivity only in the $60 \mathrm{~S}$ subunit fraction upon UV irradiation but not with untreated samples (Fig. 6A). Therefore, incorporation of radioactivity into the 605 subunit was caused by crosslinking of the flSec mRNA SECIS element to the $60 \mathrm{~S}$ subunit in the 80S-I complex. The cross-linking yield was $<1 \%$ of the flSec mRNA bound to ribosomes. Thus, it is likely that the proteins observed in Figure 5B, lane 15 were 60S subunit proteins cross-linked to the SECIS element of the flSec mRNA. No notable increase in the cross-linking yield was detected when the SECIS RNA was derivatized with randomly inserted aminoallyl-containing uridine residues bearing perfluorophenylazido groups (see Fig. 1B and C; cross-linking radius $\sim 17 \AA$ ) instead of s4U (Fig. 6B). The low cross-linking yield and its scattering among several ribosomal proteins (Fig. mRNA was not involved in aminoacyl-tRNA binding to the ribosomal A-site, whereas this was the case in the complex with the flSec mRNA (Fig. 5B, lane 15). The lack of the SECIS-ribosome cross-link, when the 80S-I complex was formed with $s 4 \mathrm{U}$-containing flPhe mRNA in the presence of SBP2, argues in favor of the A site-bound-Sec-tRNA ${ }^{\text {Sec }}$-dependent nature of the cross-link between the s4U-containing flSec mRNA and ribosomes in the 80S-I complex. This crosslink could be considered as SBP2-dependent since binding of the Sec-tRNA ${ }^{\text {Sec }}$ at the ribosomal A site was mediated by the SECIS-bound SBP2. Based on the cross-linking data, we conclude that the SECIS element of the flSec mRNA contacts the ribosome only in the 80S-I complex, whereas it establishes contacts with SBP2 in the $48 \mathrm{~S}$ preinitiation and $80 \mathrm{~S}-\mathrm{II}$ pretranslocation complexes.

Similar experiments were performed to check whether the SECIS element of the flSec mRNA could cross-link to ribosomal RNAs. After cross-linking, RRL was treated with proteinase $\mathrm{K}$ to hydrolyze proteins, and total RNA was resolved
5, lane 15) made us unable to identify the cross-linked proteins, but on the other hand, it definitely indicated the absence of rigid contact of the SECIS with the ribosome.

\section{DISCUSSION}

Deciphering the mechanism of selenocysteine incorporation during selenoprotein synthesis remains a challenging task. While most, if not all, of the numerous molecular actors involved have been identified (Allmang et al. 2009), the mechanistic issues are still shrouded in mystery. The question is even more acute when considering the case of the selenoprotein P mRNA, which contains 10-17 UGA Sec codons and two SECIS elements (Stoytcheva et al. 2006). In an attempt to increase our knowledge, in the work described here, we designed for the first time a minimal capped selenoprotein mRNA bearing photoreactive groups in the SECIS element. Its use enabled us to localize SBP2 at different translation steps and to obtain a novel insight into selenoprotein 

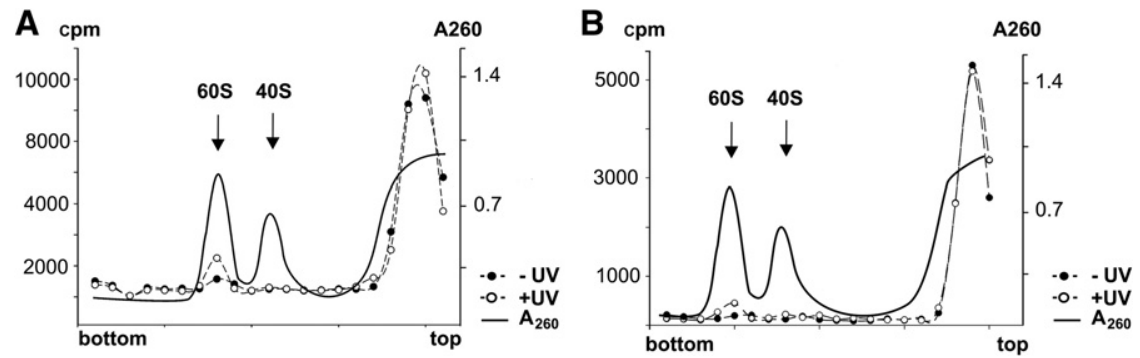

FIGURE 6. Sucrose gradient sedimentation profile of the $60 \mathrm{~S}$ and $40 \mathrm{~S}$ ribosomal subunits isolated from the irradiated $80 \mathrm{~S}$ complex formed in RRL in the presence of $5 \mathrm{mM}$ anisomycin with flSec mRNA bearing SECIS derivatized with either $(A)$ statistically distributed s4Us or $(B)$ randomly inserted $\mathrm{N}_{3} \mathrm{R}$-aaUs. Solid line, $\mathrm{A}_{260}$; dashed line, radioactivity corresponding to irradiated (open circles) and nonirradiated (closed circles) complexes. The relative error in determining the amount of radioactivity in the fractions was $\sim 10 \%$; the data are the average of the three independent experiments.

synthesis. It should be noted that, in our minimal mRNAs, the UGA Sec codon was separated from the stop codon by two triplets, a distance similar (1-3 triplets) in at least six human selenoprotein mRNAs (SelK, SelO, SelP, SelS, TRI, TRII) (Castellano et al. 2008). It is unlikely at this stage of our knowledge that the distance between the UGA Sec and the stop codon could influence the mechanism of selenocysteine incorporation into the growing polypeptide chain.

\section{Study of selenocysteine incorporation with engineered minimal selenoprotein $\mathrm{mRNA}$}

Isolated SECIS RNAs were previously used by other investigators as cross-linking probes to fish out possible molecular partners. SECIS-binding proteins such as SBP2, ribosomal protein L30, the exon-junction complex protein eIF4a3, and nucleolin were thus identified (Copeland and Driscoll 1999; Chavatte et al. 2005; Budiman et al. 2009; Miniard et al. 2010). The isolated SECIS RNA was also the mainstay to get insight into the mechanism of selenoprotein synthesis. In this respect, two models for selenocysteine insertion were proposed. In the first one, SBP2 is permanently associated with a subset of ribosomes and binds the SECIS element after the ribosome reaches a UGA Sec codon (Donovan et al. 2008). The second model marks a notable difference. SBP2 is associated with the SECIS element and, after positioning of the UGA Sec codon into the ribosomal A site, ribosomal protein L30 displaces SBP2 from the SECIS, causing conformational rearrangements in the SECIS and thus induces release of the eEFSec $\cdot S e c-t R N A^{\text {Sec }} \cdot$ GTP complex (Chavatte et al. 2005).

However, mechanistic issues are still bitterly missing to validate one model or the other. To obtain a more detailed insight into the selenocysteine insertion mechanism, we have chosen in this study an approach using minimal selenoprotein mRNAs instead of the isolated SECIS RNA (Chavatte et al. 2005; Donovan et al. 2008). The minimal selenoprotein mRNA was engineered from two RNA pieces that were sealed by splint-aided T4 DNA ligation. The mRNA was designed so cessfully used to study mRNA-ribosome interactions in various translation complexes (Graifer et al. 2004; Laletina et al. 2006; Pisarev et al. 2008; Graifer and Karpova 2012). In the present study, a minimal selenoprotein mRNA was constructed that harbored different photoreactive groups in the SECIS element: either randomly distributed 4-thiouridines or randomly inserted aminoallyl-containing uridine residues bearing perfluorophenylazido groups.

\section{SBP2 is bound to the SECIS element of selenoprotein mRNAs in translation-competent complexes}

We showed by cross-linking that SBP2 is already bound to the SECIS element of selenoprotein mRNA in the 48S initiation complex. Nevertheless, it is still unclear whether SBP2 remains free in solution and binds the SECIS element only once the selenoprotein mRNA is recruited to the 40S subunit or is permanently complexed with the selenoprotein mRNA before contacting the ribosome. The latter possibility seems more likely since SBP2 was found associated with selenoprotein mRNAs in vivo by immunoprecipitation (Copeland et al. 2000). The identification of nuclear export and localization signals in SBP2 (Papp et al. 2006) and of additional nuclear proteins participating in SECIS-SBP2 complex formation (Boulon et al. 2008) strongly suggests that SBP2 is bound to the SECIS of selenoprotein mRNA in the nucleus. Taking all this into account, plus the cross-links of SBP2 with the SECIS elements of the flSec mRNA in the 80S-II pretranslocation complex and of the flPhe mRNA in the 80S-I complex (where UUC in the A site was occupied by the cognate tRNA), one can conclude that SBP2 travels associated with the SECIS element of selenoprotein mRNA before contacting the ribosome.

\section{Nature of the SECIS-ribosome and SBP2-ribosome interactions}

According to our data, the SECIS element contacts the ribosome in the 80S-I complex where transpeptidation is blocked 
(shown by cross-linking), but these contacts are flexible, as inferred from the distribution of cross-linked SECIS over several ribosomal proteins. SBP2 is present in the 80S-I complex (shown by Western blotting), but it remains unclear whether it contacts the SECIS in this complex, because the lack of cross-link between SBP2 and the SECIS does not necessarily mean absence of SBP2-SECIS contacts. Therefore, two possibilities of SBP2 interaction in the 80S-I complex should be considered. In the first one, SBP2 in this complex could not interact with the SECIS element at all and contacted only the ribosome. It is likely that SBP2 binding to the ribosome is accompanied by conformational rearrangements in the SECIS element, leading to a decrease of SBP2 affinity to the SECIS, thus promoting SBP2 association with the $60 \mathrm{~S}$ subunit. The second possibility suggests that SBP2 was bound both to the ribosome and the SECIS; this suggestion is supported by the larger amount of SBP2 in the 80S-I complex as compared with those in $48 \mathrm{~S}$ and $80 \mathrm{~S}$-II complexes, indicating stabilization of the 80S-I complex by SBP2 contacts with both the SECIS element of the mRNA and the ribosome. However, cross-linking between SBP2 and the s4U moieties in the SECIS of the flSec mRNA did not occur for some reason. The lack of cross-link could be caused either by inappropriate orientation of the SECIS s4U moieties with respect to SBP2 in this complex (for example, SBP2 could interact with the SECIS element via the sugar-phosphate backbone) or by poor reactivity of an SBP2 amino acid residue(s) contacting a photoactivated $s 4 \mathrm{U}$. All this could happen because of either (1) conformational rearrangements in the SBP2 binding site on the SECIS (allowing SBP2 to bind both with the ribosome and the SECIS), or (2) structural changes in the SBP2 region interacting with the SECIS. Indeed, it is difficult to imagine simultaneous binding of SBP2 with the ribosome and the SECIS without such rearrangements since the SBP2 sites for SECIS and ribosome binding overlap significantly (Copeland et al. 2001; Takeuchi et al. 2009). Thus, whatever the interactions of SBP2 in the 80S-I complex, they should involve conformational changes in the SECIS element and, possibly, in SBP2. The cross-linking of SBP2 to the SECIS element of the flSec mRNA in the pretranslocation 80S-II complex indicates that, at least after transpeptidation, the SECIS element and SBP2 adopt the initial conformations favorable for cross-linking.

Thus, SBP2 could bind the ribosome either during eEFSec $\cdot S e c-t R N A{ }^{\text {Sec }} \cdot$ GTP complex delivery to the ribosomal A site or during Sec-tRNA ${ }^{\mathrm{Sec}}$ accommodation to this site. SBP2 could also be bound to the SECIS element at these steps. Worthy of note, recent data reported a higher accessibility of helix $\mathrm{H} 89$ of the $28 \mathrm{~S}$ rRNA due to conformational changes induced by SBP2 binding to the $80 \mathrm{~S}$ ribosome (Caban and Copeland 2012), and that Domain IV of elongation factor eEFSec is involved in Sec-tRNA ${ }^{\mathrm{Sec}}$ binding, interactions with SBP2, and regulating GTPase activity (Gonzalez-Flores et al. 2012). Based on these findings, the authors proposed that, when the eEFSec $\cdot S e c-$ RNA $^{\text {Sec } \cdot G T P}$ ternary complex appears near the ribosomal A site, the SECIS-bound SBP2 and helix H89 of the 28S rRNA interact with Domain IV of eEFSec to dissociate the ternary complex and to deliver the Sec-tRNA ${ }^{\mathrm{Sec}}$ to the A site (Gonzalez-Flores et al. 2012). This implies that SBP2 binds both to the SECIS and the $60 \mathrm{~S}$ ribosomal subunit before accommodation of the Sec-tRNA ${ }^{\text {Sec }}$ to the A site. Our data show that SBP2 stays bound to the ribosome and, possibly, to the SECIS after accommodation of Sec-tRNA ${ }^{\text {Sec }}$ to the A site; SBP2 dissociates from the ribosome during or after peptide bond formation, manifesting again its high affinity for the SECIS element (as shown by cross-linking of SBP2 with the SECIS in the 80S-II complex). What does make SBP2 dissociation possible? We propose that conformational changes in the $28 \mathrm{~S}$ rRNA near the peptidyl-transferase center accompanying transpeptidation propagate to the SBP2 binding site on the 60 subunit, resulting in significant lowering of SBP2 affinity for the ribosome. To decipher this more deeply and to clarify all the questions that arose, additional investigations are required that are outside the scope of this work.

The findings presented herein provide new information concerning the molecular mechanism of selenocysteine insertion into selenoproteins with regard to SBP2-SECIS, SBP2-ribosome, and SECIS-ribosome interactions. The use of minimal selenoprotein mRNA containing all the known functional parts found in natural selenoprotein mRNAs made it possible to arrive at a new point of view, stating that the SECIS of mRNA is associated with SBP2 already at the step of $48 \mathrm{~S}$ initiation complex formation. The second novelty is that SBP2 stays bound to the ribosome after Sec$\mathrm{tRNA}^{\mathrm{Sec}}$ accommodation to the A site and dissociates during transpeptidation. The third novelty is that the SECIS element in the selenoprotein mRNA contacts the $60 \mathrm{~S}$ ribosomal subunit after Sec-tRNA ${ }^{\mathrm{Sec}}$ accommodation. Lastly, our findings led us to propose that incorporation of the Sec residue into the polypeptide chain is governed by conformational rearrangements in both the SECIS and $28 \mathrm{~S}$ rRNA. Future structural and biochemical experiments will be required to provide a more complete mechanistic picture.

\section{MATERIALS AND METHODS}

\section{Synthesis of the minimal selenoprotein mRNAs}

Minimal selenoprotein mRNAs were obtained by splint-aided ligation with T4 DNA ligase of a $5^{\prime}$ RNA segment containing the $5^{\prime}$ UTR, a short coding region, and part of the $3^{\prime}$ UTR, and a $3^{\prime}$ RNA consisting of the remainder of the $3^{\prime}$ UTR with the SECIS element. The 5' RNA contained either the UGA Sec or a UUC Phe codon as the control. The whole procedure is described below.

\section{Synthesis of the $5^{\prime}$ RNAs}

The DNA template for $5^{\prime}$ RNA synthesis was obtained by PCR. A typical reaction contained $1 \mu \mathrm{M} 5^{\prime}$-UTR and $3^{\prime}$-UTR primers, and 
$0.05 \mu \mathrm{M}$ Sec or Phe primers in $50 \mu \mathrm{L}$ of DyNAzyme buffer (Finnzymes) containing $0.2 \mathrm{mM}$ dNTPs and 1 unit of DNA polymerase DyNAzyme EXT (Finnzymes). Amplification was carried out in Progene amplificator (Techne), using the following program: $94^{\circ} \mathrm{C}$ for $30 \mathrm{sec}, 55^{\circ} \mathrm{C}$ for $30 \mathrm{sec}$, and $68^{\circ} \mathrm{C}$ for $30 \mathrm{sec}(30 \mathrm{cycles}$ ). Primer sequences $\left(5^{\prime}\right.$ to $\left.3^{\prime}\right)$ are as follows: $5^{\prime}$-UTR-AAATTAAT ACGACTCACTATAGGGAGAAAAAAGAAAGAAATG, $\quad$ 3'-UTR (2'OMe-G) (2'OMe-C)-TTCCTTCGTGTCTTTGTCTTTTTTC TTTTTCTTTTCTTTCTTCT, Sec-TTCTTTTCTTTCTTCTTAG AAGAATCACATTTCTTTCTTTTTTC, Phe-TTCTTTTCTTTCTT CTTAGAAGAAGAACATTTCTTTCTTTTTTC. The resulting DNA templates were used to synthesize the RNA transcripts by T7 transcription in vitro. The resulting RNAs were purified on sephadex G15 mini-spin columns (Thermo Scientific). The RNAs were designated as $5^{\prime}$ Sec RNA and 5' Phe RNA.

Sequences of the RNAs were $5^{\prime}$-gggagaaaaaagaaagaaauguga uucuucuaagaagaaagaaaagaaaaagaaaaaagacaaagacacgaaggaaga- $3^{\prime}$ and $5^{\prime}$-ggagaaaaaagaaagaaauguucuucuucuaagaagaaagaaaagaaaaagaaaaaag acaaagacacgaaggaaga- $3^{\prime}$ for the $5^{\prime}$ Sec RNA and $5^{\prime}$ Phe RNA, respectively (coding region and stop codon are shown in bold).

\section{Synthesis of the $3^{\prime}$ RNA}

The wild type and the mutant of the glutathione peroxidase 1 (GPx1) SECIS RNA were used as 3' RNA (Fig. 1A). Mutant Mut1 converted the non-Watson-Crick base pair quartet to four Watson-Crick base pairs. Plasmids pT7Bck-GPx and pT7BckG24, encoding the WT and the Mut1 SECIS, respectively (Walczak et al. 1998), were linearized with EcoRI and used as DNA templates for the T7 transcription reaction carried out as described (Fagegaltier et al. 2000b). To obtain uniformly ${ }^{32} \mathrm{P}$-labeled RNA, $100 \mu \mathrm{Ci}$ of $\left[a^{32} \mathrm{P}\right]$ ATP $(3000 \mathrm{Ci} / \mathrm{mmol})$ were added. To synthesize RNA with randomly distributed 4-thiouridines ( $\mathrm{s} 4 \mathrm{U}$ ), the UTP concentration was reduced to $2 \mathrm{mM}$, and s4UTP was added to $0.5 \mathrm{mM}$. Taking into account that the $s 4 \mathrm{U}$ insertion efficiency is $\sim 4.5$ times less than that of U (Dubreuil et al. 1991), and the concentration of s4UTP was four times lower than that of UTP, one can assume that no more than two out of the 32 uridine residues in the GPx1 SECIS (and flanking sequences) were substituted by s $4 \mathrm{U}$ residues. The same procedure was applied to synthesize uniformly ${ }^{32} \mathrm{P}$-labeled RNA with randomly distributed aminoallyl-containing-uridine residues bearing perfluorophenylazido groups $\left(\mathrm{N}_{3} \mathrm{R}-\mathrm{aaU}\right)$. Prior to synthesis, $\mathrm{N}_{3} \mathrm{R}$-aaUTP was synthesized by benzoylation of the aliphatic amino group of aaUTP with the N-oxysuccinimide ester of 4-azidotetrafluorobenzoic acid, as described (Fig. 1C; Graifer and Karpova 2012). RNA purification was carried out as above.

\section{Preparation of full-length minimal mRNAs and their photoreactive derivatives by splint-aided T4 DNA ligation}

flSec and flPhe mRNAs (Fig. 1A) were obtained by splint-aided ligation of the $5^{\prime}$ and $3^{\prime}$ RNAs with T4 DNA ligase. A typical reaction mixture contained 150 pmol of $5^{\prime}$ RNA, 150 pmol of the splint oligonucleotide 5'-GTGATCACCAAGCCCGCTTCCTTCGTGTCT$3^{\prime}$ and 120 pmol of $3^{\prime}$ RNA (SECIS GPx1, WT or mutant), 20 units of RNasin, and 100 units of T4 DNA ligase (Epicentre) in $100 \mu \mathrm{L}$ of T4 DNA ligase buffer (Epicentre). After gel purification and elution, the yield of the ligated product was $10 \%-12 \%$. Capping of mRNA was carried out using the ScripCap m7G Capping System (Epicentre). To obtain the mRNAs in large quantities, the products of the 5' RNA and 3' RNA T4 DNA ligation were reverse-transcribed. The resulting cDNAs were PCR-amplified and used for T7 transcription. The mRNA was ${ }^{32} \mathrm{P}$-labeled and purified as described above.

The sequences of the resulting minimal RNAs were $5^{\prime}$-ggga gaaaaaagaaagaaaugugauucuucuaagaagaaagaaaagaaaaagaaaaaagac aaagacacgaaggaagagggcuuggugaucacuggcugcccuccgggggggagguuuuисca ugacguguинссисиаааиииасаиggagaаacaccugauинссаgaаaаaиссссисаg augggcgcugguaccgagcucg- $3^{\prime}$ for the flSec mRNA and 5'-gggagaaaaaag aaagaaauguucuucuucuaagaagaaagaaaagaaaagaaaaagacaaagacacg aaggaagagggcuuggugaucacuggcugcccuccgggggggagguuuuuccaugacgug

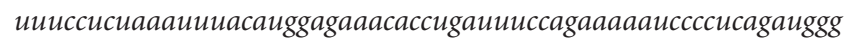
cgcugguaccgagcuc- $3^{\prime}$ for the flPhe mRNA (coding region and stop codon are shown in bold; a part of GPx1 $3^{\prime}$ UTR containing SECIS is shown in italics).

Photoreactive derivatives of flSec and flPhe mRNAs were obtained using the same procedure; uniformly ${ }^{32} \mathrm{P}$-labeled $3^{\prime}$ RNA (SECIS GPx1; 25,000 cpm/pmol) bearing statistically introduced photoreactive groups was used as $3^{\prime}$ RNA. Purification and capping of the mRNA derivatives were carried out as described above. The yield of the photoreactive derivatives was $10 \%-12 \%$.

\section{Preparation of recombinant proteins}

The C-terminal part of human SBP2 (aa 343-854) fused to an $\mathrm{N}$-terminal $6 \times$ His tag was expressed in Escherichia coli BL21(DE3) RIL strand (Novagene) as described (Takeuchi et al. 2009). Recombinant ribosomal protein L30 was kindly provided by A. Shmakova (Institute of Chemical Biology and Fundamental Medicine, Siberian Branch of the Russian Academy of Sciences).

\section{Toe-printing assay}

The mixture containing $50 \%(\mathrm{v} / \mathrm{v})$ of micrococcal nuclease-treated rabbit reticulocyte lysate (Promega), 10 units of RNasin, $0.25 \mathrm{mM}$ amino acid mixture in $10 \mu \mathrm{L}$ of buffer A (20 mM HEPES-KOH $\mathrm{pH} 7.8,100 \mathrm{mM}$ KOAc, $2 \mathrm{mM} \mathrm{Mg}[\mathrm{OAc}]_{2}, 0.25 \mathrm{mM}$ spermidine, and $10 \mathrm{mM}$ sodium creatine phosphate), $1 \mathrm{mM}$ ATP, $0.1 \mu \mathrm{M}$ recombinant C-terminal SBP2, and $2 \mathrm{mM}$ GMPPNP or $0.5 \mathrm{mM}$ GTP, together with antibiotic (either $2 \mathrm{mM}$ emetine or $5 \mathrm{mM}$ anisomycin) was preincubated for $5 \mathrm{~min}$ at $30^{\circ} \mathrm{C}$. Then, capped mRNA $(0.3$ pmol) was added, and the mixture was incubated for an additional $5 \mathrm{~min}$ at $30^{\circ} \mathrm{C}$. The reverse transcription and the resulting cDNA products analysis were carried out as described (Dmitriev et al. 2003). After electrophoresis, the gel was dried, exposed to a BioRad Phosphorimager plate, and analyzed using the QuantityOne program (BioRad).

\section{mRNA-ribosome binding in rabbit reticulocyte lysate}

The mixture contained $100 \mu \mathrm{L}$ micrococcal nuclease-treated RRL, 10 units of RNasin, and $0.25 \mathrm{mM}$ amino acid mixture in $200 \mu \mathrm{L}$ of buffer A. Prior to adding the mRNA, the mixture was supplemented with recombinant SBP2 $(0.25 \mu \mathrm{M})$ and $5 \mathrm{mM}$ anisomycin, and incubated at $30^{\circ} \mathrm{C}$ for $5 \mathrm{~min}$. After mRNA addition (concentration of the mRNA was $0.05,0.1,0.15,0.25$, or $0.35 \mu \mathrm{M}$; specific radioactivity was $\sim 10,000 \mathrm{cpm} / \mathrm{pmol}$ ), the mixture was incubated at $30^{\circ} \mathrm{C}$ for $15 \mathrm{~min}$, then layered onto a $5 \%-40 \%$ sucrose gradient in 
buffer B (20 mM HEPES-KOH pH 7.8, $100 \mathrm{mM}$ KOAc, and $2 \mathrm{mM}$ $\mathrm{Mg}[\mathrm{OAc}]_{2}$ ) and centrifuged at $52,000 \mathrm{rpm}$ for $2.5 \mathrm{~h}$ at $4^{\circ} \mathrm{C}$ in an SW60 rotor. After centrifugation, gradient fractions were collected. To analyze the binding of mRNA with the ribosome, the radioactivity of each gradient fraction was measured, and the binding efficiency was calculated ( $\mathrm{mol}$ of $\mathrm{mRNA} / \mathrm{mol}$ of ribosomes).

\section{SBP2 content in ribosomal complexes}

$80 \mathrm{~S}$ or $48 \mathrm{~S}$ complexes were assembled in $200 \mu \mathrm{L}$ of buffer A $(50 \% \mathrm{v} / \mathrm{v}$ of RRL) as described in the previous section, except that the mixtures were supplemented with $50 \mathrm{pmol}$ of SBP 2 and 50 pmol of ${ }^{32} \mathrm{P}$-labeled mRNA (flSec mRNA, Mut1 mRNA, or 5' Phe mRNA; 10,000 cpm/ pmol). Ribosomal complexes were isolated by centrifugation in the sucrose density gradient as described above. After centrifugation and fractionation, fractions corresponding to ribosomal complexes were TCA-precipitated. The resuspended pellet was loaded onto $10 \%$ SDS-PAGE, which was blotted onto Immobilon membranes (Millipore). The SBP2 signal was detected with rabbit polyclonal anti-SBP2 antibodies, which were shown beforehand not to crossreact with ribosomal proteins (1/2500 dilution). Membranes were treated with anti-rabbit HRP-conjugated secondary antibody (1/ 10,000 dilution), revealed with the ECL-plus kit (GE Healthcare), and exposed to either X-ray film or ChemiDoc XRS (BioRad).

\section{tRNA $3^{\prime}$ end post-labeling}

Ribosomal complexes 48S, 80S-I, and 80S-II with flSec mRNA and respective control complexes without mRNA added were assembled, isolated, and ethanol-precipitated as described above. Control 80S-I complexes were also assembled on Mut 1 mRNA in the presence of SBP2 and on flSec mRNA in the absence of SBP2. The pellet was dissolved in $100 \mu \mathrm{L}$ of $0.1 \%$ SDS containing $1 \mathrm{mM}$ EDTA and incubated at $37^{\circ} \mathrm{C}$ for $10 \mathrm{~min}$. After phenol-chloroform extraction and ethanol precipitation, the resulting total RNA was dissolved in $40 \mu \mathrm{L}$ of $\mathrm{H}_{2} \mathrm{O}$. One quarter of the extracted RNA was incubated in $50 \mu \mathrm{L}$ of $150 \mathrm{mM} \mathrm{NaOAc}$ pH 5.5 containing $10 \mathrm{mM} \mathrm{CuSO}_{4}$ as described (Roessler et al. 1989), ethanol-precipitated, dissolved in $20 \mu \mathrm{L}$ of $\mathrm{H}_{2} \mathrm{O}$ and $3^{\prime}$ end-labeled with $20 \mu \mathrm{Ci}$ of $\left[5^{\prime}-^{32} \mathrm{P}\right] \mathrm{pCp}$ using T4 RNA ligase. The rest of the total RNA obtained from the 80S-II complex was incubated in $50 \mathrm{mM}$ Tris- $\mathrm{HCl} \mathrm{pH} 9.0$ for $1 \mathrm{~h}$ at $25^{\circ} \mathrm{C}$, precipitated, and subjected to $3^{\prime}$ end labeling, too. The bovine tRNA $^{\text {Sec }}$ marker was obtained by T7 transcription after Bst2U I (SibEnzyme) plasmid linearization (Sturchler et al. 1995). Marker RNAs (tRNA ${ }^{\mathrm{Sec}}$, tRNA ${ }^{\mathrm{Met}}$, flSec RNA, 5S rRNA, and 5.8S rRNA) were $3^{\prime}$ labeled with $\left[5^{\prime}-{ }^{32} \mathrm{P}\right] \mathrm{pCp}$. The resulting labeled RNAs were analyzed by $10 \%$ denaturing PAGE; the gel was treated and analyzed as described above.

\section{mRNA-ribosomes cross-linking in RRL}

The mRNA•ribosome complexes were assembled in $120 \mu \mathrm{L}$ RRL as described in the previous section, except that the minimal mRNA harbored an s4U-containing uniformly ${ }^{32} \mathrm{P}$-labeled SECIS. To generate cross-links, reaction mixtures were placed on ice in 96-well plates containing $25-\mu \mathrm{L}$ aliquots and irradiated for $2 \mathrm{~min}$ with a SpotCure UV lamp $(\lambda>290 \mathrm{~nm})$, shorter wavelengths being cut off using a thin glass filter (in order to avoid direct UV-induced cross-linking). 2-mercaptoethanol was added to the irradiated complexes to $0.17 \%$ final concentration. Control reactions were not irradiated and kept on ice. Prior to complex formation, the activity of the photoreactive groups introduced into the SECIS of flSec and flPhe mRNAs was examined by cross-linking the mRNA derivatives $(0.05 \mu \mathrm{M})$ to SBP2 $(0.15 \mu \mathrm{M})$ under conditions described above. The cross-linked products were analyzed by $14 \%$ SDSPAGE after preliminary RNase A hydrolysis of the RNA moieties attached to proteins. To reveal the cross-links, gels were fixed in ethanol/AcOH, dried, and exposed to a PhosphorImager plate and analyzed using the QuantityOne program (BioRad). The same procedure was carried out to control the activity of the photoreactive groups introduced into the SECIS RNA before using the SECIS RNA derivatives for ligation with the $5^{\prime}$ RNA moiety to obtain the full-length minimal mRNA.

\section{Analysis of cross-linked proteins and rRNA}

To analyze protein cross-links, mixtures were layered after irradiation onto $10 \%-30 \%$ sucrose gradients in buffer B and centrifuged at $22,000 \mathrm{rpm}$ at $4^{\circ} \mathrm{C}$ for $17 \mathrm{~h}$ in an SW40 rotor. After centrifugation, fractions corresponding to $80 \mathrm{~S}$ or $48 \mathrm{~S}$ complexes were TCA-precipitated. The pellets were dissolved in $50 \mu \mathrm{L}$ of water, $10 \mu \mathrm{L}$ were taken for Western blot analysis, and the remainder was treated with $0.1 \%$ SDS containing $0.5 \mathrm{mM}$ EDTA and incubated at $37^{\circ} \mathrm{C}$ for $10 \mathrm{~min}$ to dissociate ribosomal particles into proteins and rRNAs. Then, $10 \mu \mathrm{g}$ of RNase A (Sigma) were added to hydrolyze the RNA. After incubation $\left(1 \mathrm{~h}, 37^{\circ} \mathrm{C}\right)$, mixtures were divided into two parts. The proteins from one half were precipitated with six volumes of acetone, while the other half was treated with $10 \mu \mathrm{g}$ of proteinase $\mathrm{K}$, incubated for an additional $30 \mathrm{~min}$ at $37^{\circ} \mathrm{C}$, and precipitated with acetone. Samples were analyzed as described above. After electrophoresis, gels were handled as described above. SBP2-flSec mRNA cross-links were assessed by immunoprecipitation as in Babaylova et al. (2009).

To identify cross-links with rRNA, $30 \mu \mathrm{L}$ of each mixture were diluted after irradiation with two volumes of $0.3 \mathrm{M} \mathrm{NaOAc} \mathrm{pH} 5.5$ containing $1 \%$ SDS and $0.5 \mathrm{mM}$ EDTA, and incubated for $15 \mathrm{~min}$ at $37^{\circ} \mathrm{C} ; 30 \mu \mathrm{g}$ of proteinase $\mathrm{K}$ were then added, and reactions were incubated for $30 \mathrm{~min}$ at $37^{\circ} \mathrm{C}$. After phenol-chloroform extraction, the rRNA was ethanol-precipitated and loaded onto 5\% denaturating PAGE. Gels were stained with ethidium bromide and visualized by ChemiDoc. The gel was then dried, exposed to PhosphorImager plate, and analyzed by densitometry using the QuantityOne software (BioRad). The SBP2 content in each complex was analyzed by Western blotting as described above.

\section{Analysis of cross-link distribution between ribosomal subunits}

To determine which ribosomal particle contacts the SECIS element, ribosome-flSec mRNA complexes were formed in RRL in the presence of anisomycin and irradiated as described above. Control reactions were not irradiated and were kept on ice. 80S ribosomal complexes were isolated by $10 \%-30 \%$ sucrose gradient centrifugation as described above. Fractions corresponding to $80 \mathrm{~S}$ complexes were ethanol-precipitated. The pellets were dissolved in $100 \mu \mathrm{L}$ of buffer C (20 mM Tris-HCl pH 7.5, $3 \mathrm{mM} \mathrm{MgCl}_{2}, 100 \mathrm{mM} \mathrm{KCl}$, and $0.15 \mathrm{mM}$ EDTA) and $30 \mathrm{pmol}$ of $40 \mathrm{~S}$ and 40 pmol of $60 \mathrm{~S}$ carrier subunits were added together with puromycin $(0.5 \mathrm{mM}$ final 
concentration), and the mixture was kept on ice for $10 \mathrm{~min}$. Ribosomal subunits were dissociated by increasing the $\mathrm{KCl}$ concentration to $450 \mathrm{mM}$, with subsequent incubation for $30 \mathrm{~min}$ at $37^{\circ} \mathrm{C}$ and then centrifuged on $10 \%-30 \%$ sucrose gradient for $17 \mathrm{~h}$ at 25,000 rpm in buffer C containing $450 \mathrm{mM} \mathrm{KCl}$. Radioactivity in each gradient fraction was measured, and the extent of the subunit(s) modification was calculated.

\section{ACKNOWLEDGMENTS}

We thank C. Allmang (IBMC, Strasbourg) for helpful discussion, advice, and a gift of materials. We thank A. Schweigert and S. Baudrey for technical assistance. O.K. was a cosupervised Ph.D. student with the Institute of Chemical Biology and Fundamental Medicine and the Universite de Strasbourg, partly supported by the French government. This work was supported in part by the ARCUS and Supramolecular Chemistry programs (to G.K. and A.K.). It was carried out under the auspices of the Laboratoire International Associé LIA NUCPROT and supported by the Russian Foundation for Basic Research (grant 12-04-93111-CNRSL_a to G.K.).

Received October 12, 2012; accepted May 15, 2013.

\section{REFERENCES}

Allmang C, Carbon P, Krol A. 2002. The SBP2 and 15.5 kD/Snu13p proteins share the same RNA binding domain: Identification of SBP2 amino acids important to SECIS RNA binding. RNA 8: $1308-1318$.

Allmang C, Wurth L, Krol A. 2009. The selenium to selenoproteins pathway in eukaryotes: More molecular pathways than anticipated. Biochim Biophys Acta 1790: 1415-1423.

Anthony DD, Merrick WC. 1992. Analysis of 40S and 80S complexes with mRNA as measured by sucrose density gradients and primer extension inhibition. J Biol Chem 267: 1554-1562.

Babaylova E, Graifer D, Malygin A, Stahl J, Shatsky I, Karpova G. 2009. Positioning of subdomain IIId and apical loop of domain II of the hepatitis C IRES on the human 40S ribosome. Nucleic Acids Res 37: 2126-2141.

Böck A, Rother M, Leibundgut M, Ban N. 2006. Selenium metabolism in prokaryotes. In Selenium: Its molecular biology and role in human health, 2nd ed. (ed. DL Hatfield, et al.), pp. 9-28. Springer Verlag, New York.

Boulon S, Marmier-Gourrier N, Pradet-Balade B, Wurth L, Verheggen C, Jady BE, Rothe B, Pescia C, Robert MC, Kiss T, et al. 2008. The Hsp90 chaperone controls the biogenesis of L7Ae RNPs through conserved machinery. J Cell Biol 180: 579-595.

Bubenik JL, Driscoll DM. 2007. Altered RNA binding activity underlies abnormal thyroid hormone metabolism linked to a mutation in selenocysteine insertion sequence-binding protein 2. J Biol Chem 282: 34653-34662.

Budiman ME, Bubenik JL, Miniard AC, Middleton LM, Gerber CA, Cash A, Driscoll DM. 2009. Eukaryotic initiation factor 4a3 is a selenium-regulated RNA-binding protein that selectively inhibits selenocysteine incorporation. Mol Cell 35: 479-489.

Bulygin K, Chavatte L, Frolova L, Favre A, Karpova G. 2005. The first position of a codon placed in the A site of the human ribosome contacts nucleotide C1696 of the $18 \mathrm{~S}$ rRNA as well as proteins S2, S3, S3a, S30 and S15. Biochemistry 44: 2153-2162.

Caban K, Copeland PR. 2012. SECIS binding protein 2 alters the conformational dynamics of residues involved in tRNA accommodation in 80S ribosomes. J Biol Chem 287: 10664-10673.

Caban K, Kinzy SA, Copeland PR. 2007. The L7Ae RNA binding motif is a multifunctional domain required for the ribosome-dependent sec incorporation activity of Sec insertion sequence binding protein 2. Mol Cell Biol 27: 6350-6360.

Castellano S, Gladyshev VN, Guigo R, Berry MJ. 2008. SelenoDB 1.0: A database of selenoprotein genes, proteins and SECIS elements. Nucleic Acids Res 36: D332-D338.

Chambers I, Frampton J, Goldfarb P, Affara N, McBain W, Harrison PR. 1986. The structure of the mouse glutathione peroxidase gene: The selenocysteine in the active site is encoded by the 'termination' codon, TGA. EMBO J 5: 1221-1227.

Chavatte L, Brown BA, Driscoll DM. 2005. Ribosomal protein L30 is a component of the UGA-selenocysteine recoding machinery in eukaryotes. Nat Struct Mol Biol 12: 408-416.

Cléry A, Bourguignon-Igel V, Allmang C, Krol A, Branlant C. 2007. An improved definition of the RNA-binding specificity of SECIS-binding protein 2, an essential component of the selenocysteine incorporation machinery. Nucleic Acids Res 35: 1868-1884.

Copeland PR, Driscoll DM. 1999. Purification, redox sensitivity, and RNA binding properties of SECIS-binding protein 2, a protein involved in selenoprotein biosynthesis. J Biol Chem 274: 2544725454.

Copeland PR, Driscoll DM. 2002. Purification and analysis of selenocysteine insertion sequence-binding protein 2. Methods Enzymol 347: 40-49.

Copeland PR, Fletcher JE, Carlson BA, Hatfield DL, Driscoll DM. 2000. A novel RNA binding protein, SBP2, is required for the translation of mammalian selenoprotein mRNAs. EMBO J 19: 306-314.

Copeland PR, Stepanik VA, Driscoll DM. 2001. Insight into mammalian selenocysteine insertion: Domain structure and ribosome binding properties of Sec insertion sequence binding protein 2. Mol Cell Biol 21: 1491-1498.

Dmitriev S, Pisarev A, Rubtsova M, Dunaevsky Y, Shatsky I. 2003. Conversion of $48 \mathrm{~S}$ translation preinitiation complexes into $80 \mathrm{~S}$ initiation complexes as revealed by toeprinting. FEBS Let 533: 99-104.

Donovan J, Caban K, Ranaweera R, Gonzalez-Flores JN, Copeland PR. 2008. A novel protein domain induces high affinity selenocysteine insertion sequence binding and elongation factor recruitment. $J$ Biol Chem 283: 35129-35139.

Dubreuil YL, Expert-Bezançon A, Favre A. 1991. Conformation and structural fluctuations of a 218 nucleotides long rRNA fragment: 4-thiouridine as an intrinsic photolabelling probe. Nucleic Acids Res 19: 3653-3660.

Fagegaltier D, Hubert N, Yamada K, Mizutani T, Carbon P, Krol A. 2000a. Characterization of $\mathrm{mSelB}$, a novel mammalian elongation factor for selenoprotein translation. EMBO J 19: 4796-4805.

Fagegaltier D, Lescure A, Walczak R, Carbon P, Krol A. 2000 b. Structural analysis of new local features in SECIS RNA hairpins. Nucleic Acids Res 28: 2679-2689.

Fletcher J, Copeland P, Driscoll D, Krol A. 2001. The selenocysteine incorporation machinery: Interactions between the SECIS RNA and the SECIS-binding protein SBP2. RNA 10: 1442-1453.

Gonzalez-Flores JN, Gupta N, DeMong LW, Copeland PR. 2012. The selenocysteine-specific elongation factor contains a novel and multi-functional domain. J Biol Chem 287: 38936-38945.

Graifer DM, Karpova GG. 2012. Structural and functional topography of human ribosome. Acta Biochim Biophys Sin 44: 281-299.

Graifer D, Molotkov M, Styazhkina V, Demeshkina N, Bulygin K, Eremina A, Ivanov A, Laletina E, Ven'yaminova A, Karpova G. 2004. Variable and conserved elements of human ribosomes surrounding the mRNA at the decoding and upstream sites. Nucleic Acids Res 32: 3282-3293.

Jimenez A, Carrasco L, Vazquez D. 1977. Enzymic and nonenzymic translocation by yeast polysomes. Site of action of a number of inhibitors. Biochemistry 16: 4727-4730.

Kozak M. 1998. Primer extension analysis of eukaryotic ribosomemRNA complexes. Nucleic Acids Res 26: 4853-4859.

Laletina E, Graifer D, Malygin A, Ivanov A, Shatsky I, Karpova G. 2006. Proteins surrounding hairpin IIIe of the hepatitis $\mathrm{C}$ virus internal ribosome entry site on the human $40 \mathrm{~S}$ ribosomal subunit. Nucleic Acids Res 34: 2027-2036. 


\section{Kossinova et al.}

Lapidot Y, de Groot N. 1972. The chemical synthesis and biochemical properties of peptidyl-tRNA. ProgNucleic Acid Res Mol Biol 12: 189-225.

Lescure A, Allmang C, Yamada K, Carbon P, Krol A. 2002. cDNA cloning, expression pattern and RNA binding analysis of human selenocysteine insertion sequence (SECIS) binding protein 2. Gene 291: 279-285.

Lescure A, Rederstorff M, Krol A, Guicheney P, Allamand V. 2009. Selenoprotein function and muscle disease. Biochem Biophys Acta 90: $1569-1574$.

Miniard AC, Middleton LM, Budiman ME, Gerber CA, Driscoll DM. 2010. Nucleolin binds to a subset of selenoprotein mRNAs and regulates their expression. Nucleic Acids Res 38: 4807-4820.

Papp LV, Lu J, Striebel F, Kennedy D, Holgrem A, Khanna KK. 2006. The redox state of SECIS binding protein 2 controls its localization and selenocysteine incorporation function. Mol Cell Biol 26: 4895-4910.

Papp LV, Lu J, Holgrem A, Khanna KK. 2007. From selenium to selenoproteins: Synthesis, identity, and their role in human health. Antioxid Redox Signal 9: 775-806.

Pisarev AV, Kolupaeva VG, Yusupov MM, Hellen CUT, Pestova TV. 2008. Ribosomal position and contacts of mRNA in eukaryotic translation initiation complexes. EMBO J 27: 1609-1621.

Roessler JR, Xu C, Payne RC, Surratt CK, Hecht SM. 1989. Preparation of the misacylated aminoacyl-tRNA(Phe)'s useful as probes of the ribosomal acceptor site. Biochemistry 28: 5185-5195.
Schofield P, Zamecnik P. 1968. Cupric ion catalysis in hydrolysis of aminoacyl-tRNA. Biochim Biophys Acta 155: 410-416.

Stoytcheva JZ, Tujebajeva RM, Harney JW, Berry MJ. 2006. Efficient incorporation of multiple selenocysteines involves an inefficient decoding step serving as a potential translational checkpoint and ribosome bottleneck. Mol Cell Biol 26: 9177-9184.

Sturchler C, Hubert N, Totsuka T, Mizutani T, Carbon P, Krol A. 1995. Selenocysteylation in eukaryotes necessitates the uniquely long aminoacyl acceptor stem of selenocysteine tRNA ${ }^{\text {Sec }}$. J Biol Chem 270: 18570-18574.

Takeuchi A, Schmitt D, Chapple C, Babaylova E, Karpova G, Guigo R, Krol A, Allmang C. 2009. A short motif in Drosophila SECIS Binding Protein 2 provides differential binding affinity to SECIS RNA hairpins. Nucleic Acids Res 37: 2126-2141.

Tujebajeva RM, Copeland PR, Xu XM, Carlson BA, Harney JW, Driscoll DM, Hatfield DL, Berry MJ. 2000. Decoding apparatus for eukaryotic selenocysteine insertion. EMBO Rep 1: 158163.

Walczak R, Westhof E, Carbon P, Krol A. 1996. A novel RNA structural motif in selenocysteine insertion element of eukaryotic selenoprotein mRNAs. RNA 2: 367-379.

Walczak R, Carbon P, Krol A. 1998. An essential non-Watson-Crick base pair motif in $3^{\prime} \mathrm{UTR}$ to mediate selenoprotein translation. RNA 4: 74-84.

Zhang Y, Gladyshev VN. 2011. Comparative genomics of trace element dependence in biology. J Biol Chem 286: 23623-23629. 

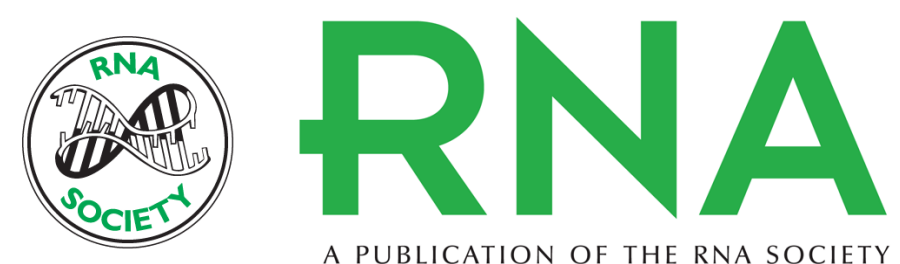

A PUBLICATION OF THE RNA SOCIETY

\title{
A novel insight into the mechanism of mammalian selenoprotein synthesis
}

Olga Kossinova, Alexey Malygin, Alain Krol, et al.

RNA 2013 19: 1147-1158 originally published online June 20, 2013

Access the most recent version at doi:10.1261/rna.036871.112

\begin{abstract}
References This article cites 46 articles, 19 of which can be accessed free at: http://rnajournal.cshlp.org/content/19/8/1147.full.html\#ref-list-1

Creative This article is distributed exclusively by the RNA Society for the first 12 months after the Commons full-issue publication date (see http://rnajournal.cshlp.org/site/misc/terms.xhtml). After 12 License months, it is available under a Creative Commons License (Attribution-NonCommercial 3.0 Unported), as described at http://creativecommons.org/licenses/by-nc/3.0/.
\end{abstract}

Email Alerting Receive free email alerts when new articles cite this article - sign up in the box at the Service top right corner of the article or click here.

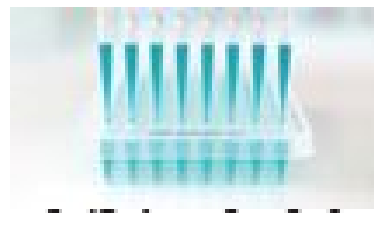

\section{Providing Precise Solutions for} your research.

To subscribe to RNA go to:

http://rnajournal.cshlp.org/subscriptions

(C) 2013; Published by Cold Spring Harbor Laboratory Press for the RNA Society 